\title{
Causality between Money and Prices: Evidence from Pakistan
}

\author{
FAZAL HUSAIN and TARIQ MAHMOOD
}

\section{INTRODUCTION}

The relationship between money and prices has been a debated issue among economic schools of thought particularly between the Monetarists and the Keynesians. The monetarists claim that changes in money stocks cause changes in price levels. In other words, the direction of causation runs from money to prices implying that prices can be controlled through money supply. The keynesians, on the other hand, argue that money is important but is not responsible for changes in price levels. Instead, structural factors play important role suggesting that money supply is not an effective instrument to control price changes.

The causal relationship between money and prices has been extensively tested in various countries. For example, Brillembourg and Khan (1979) examined this relationship in USA. Using Sims procedure for the period 1870-1975, they found unidirectional causality running from money to prices. Similar directions of causation are reported by Lee and Li (1983) and Ramachandran and Kamaiah (1992) who investigated the causal relationship in Singapore and India respectively. On the other hand, Aghevli and Khan (1978), while investigating the causal relationship in Brazil, Columbia, the Dominican Republic, and Thailand, found bidirectional causality between money and prices in these countries.

The money-price relationship has also been investigated in Pakistan. Ali (1986) found the validity of the Quantity Theory of Money in predicting price levels. The causal relationship was formally investigated by Jones and Khilji (1988). Using monthly data on alternative measures of money, M1 and M2, and prices, Wholesale Price Index (WPI) and Consumer Price Index (CPI), for the period 1973-1985 and

Fazal Husain and Tariq Mahmood are both Research Economists at the Pakistan Institute of Development Economics, Islamabad. 
applying Granger test, they found significant impacts of money lags on WPI and CPI lags on money measures without any feedback. On the other hand, Khan and Siddiqui (1990), using Sims procedure and quarterly data for the period 1972-1981, found unidirectional causality from M1 to CPI but bidirectional between M2 and CPI. Finally, Bengali, Khan, and Sadaqat (1997), taking care of time series properties and using quarterly data from 1972-1990, found bidirectional causality between money measures (M1 and M2) and CPI.

This paper re-examines the causal relationship between money and prices in Pakistan using recent data on money and prices and taking care of time series properties. Earlier studies, with the exception of Bengali et al. (1997), ignore the time series aspect and may lead to wrong conclusion regarding causality. None of the studies uses data beyond 1990 whereas, the 1990s has been the period of high growth in prices and money as well as banking and financial sector reforms.

The paper is organised as follows. The next section describes the data sources. Section III outlines the methodology to test for the time series properties as well as the causality. The empirical results are presented in Section IV. The last section contains the summary and conclusion.

\section{DATA SOURCES}

Monthly data on money stocks and prices were used from July 1981 to June 1998. Three measures of money stocks were taken. These are,

$$
\begin{aligned}
& \text { M0 }=\text { Currency in Circulation. } \\
& \text { M1 }=\text { M0 + Demand Deposits + Other deposits with SBP. } \\
& \text { M2 }=\text { M1 + Time Deposits + Residents Foreign Currency Deposits. }
\end{aligned}
$$

The data on these measures, in million rupees, were taken from various issues of the Monthly Statistical Bulletin of the State Bank of Pakistan (SBP).

The data on two measures of prices, Wholesale Price Index (WPI) and Consumer Price Index (CPI), with base period 1980-81, were taken from the various issues of the Monthly Statistical Bulletin of the Federal Bureau of Statistics, Statistics Division. The WPI is constructed by the wholesale prices of food, raw materials, fuel and lubricants, manufactures, and building materials. The CPI is based on retail prices covering 61 markets in 25 cities and 460 commodities.

\section{METHODOLOGY}

In the first step, the stationarity of variables included in the analysis was tested by a Unit Root test. In this context, the Augmented Dickey Fuller (ADF) test was used and three models were estimated. 
Model I (without any constant and trend)

$$
\Delta Y_{t}=\rho^{*} Y_{t-1}+\sum_{i=1}^{p} \delta_{i} \Delta Y_{t-i}+e_{t} \quad \ldots \quad \ldots \quad \ldots \quad \ldots
$$

Model II (with constant but no trend)

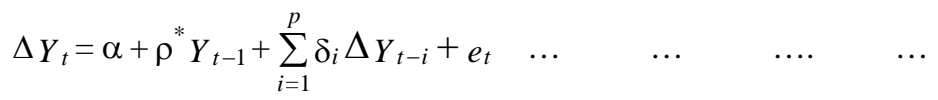

Model III (with constant and trend)

$$
\Delta Y_{t}=\alpha+\beta t+\rho^{*} Y_{t-1}+\sum_{i=1}^{p} \delta_{i} \Delta Y_{t-i}+e_{t} \quad \ldots \quad \ldots \quad \ldots
$$

The ADF statistic is the $t$-value associated with the estimated coefficient of $\rho^{*}$. The acceptance of null hypothesis $\left(\mathrm{H}_{0}: \rho^{*}=0\right)$ implies the presence of unit root which in turn implies nonstationarity. The hypothesis is rejected if $\rho^{*}$ is negative and significant. The test was performed for all the series of money and prices where both the original series and the differences of the series were tested for stationarity.

The co-integration between the two series was tested by running the OLS regression, called the co-integrating regression:

$$
\begin{array}{lllllll}
Y_{t}=\alpha+\beta X_{t}+e_{t} & \ldots & \ldots & \ldots & \ldots & \ldots & \ldots
\end{array}
$$

Then the series of residuals, $e_{t}$, from this regression was tested for stationary. Stationarity in $e_{t}$ implies co-integration between $Y_{t}$ and $X_{t}$, and can be tested in many ways, as discussed in Engle and Granger (1987). One way is to apply the ADF test (defined above) on $e_{t}$. The second and a quick way is to look at the Durbin-Watson statistic of the co-integrating regression. If it is close to zero then this implies that $e_{t}$ is not stationary and therefore $Y_{t}$ and $X_{t}$ are not co-integrated. Engle and Granger (1987), though, proposed several methods to test for co-integration, however, recommended the ADF procedure.

The acceptance of co-integration between two series implies that there exists a long run relationship between them. However, this relationship may be disturbed by short run deviations from equilibrium and thus an Error Correction Model (ECM) may be an appropriate framework which is an extension of the Granger causality test where an error correction term is introduced into the test, that is,

$$
\begin{array}{llll}
\Delta Y_{t}=\alpha_{1}+\rho_{1} e_{t-1}+\sum_{i=1}^{p} \beta_{i} \Delta Y_{i-1}+\sum_{j=1}^{q} \delta_{j} \Delta X_{j-1} & \ldots & \ldots \\
\Delta X_{t}=\alpha_{2}+\rho_{2} e_{t-1}+\sum_{i=1}^{p} \beta_{i} \Delta Y_{i-1}+\sum_{j=1}^{q} \delta_{j} \Delta X_{j-1} & \ldots & \ldots
\end{array}
$$

where $e_{t-1}$ is an error correction term representing the long run relationship. $\rho_{1}$ and $\rho_{2}$ are considered the speed of adjustment coefficients. Furthermore, at least one of these 
coefficients must be significant in order the ECM to hold. If both coefficients are significant, this will suggest that both series exert long run relationship, that is, there exists a feedback mechanism between them. If, however, only $\rho_{1}$ is found to be significant, this will suggest that $X$ off drives $Y$ toward long run equilibrium but not the other way around. Moreover, these coefficients must be negative in order the last period positive deviation from long run trend to have negative effect in this period and thus pushing it back toward the trend.

The lagged terms of $\Delta Y_{t}$ and $\Delta X_{t}$, appeared as explanatory variables, indicate short run dynamics or cause and effect relationship between the two series. Thus, if the lagged coefficients of $\Delta X_{t}$ appear to be significant in the regression of $\Delta \mathrm{Y}_{t}$, this means that $X$ affects $Y$. Similarly, the opposite holds if the lagged coefficients $\Delta \mathrm{Y}_{t}$ are significant in $\Delta X_{t}$. If none of the lagged coefficient is significant anywhere this implies that there is no cause and effect relationship between the two series.

\section{EMPIRICAL RESULTS}

In the first step all the series were tested for the unit roots. In this context, the ADF was applied to both the original series (in log) and the first differences. The results are reported in Table 1.

The results suggest the acceptance of the presence of unit roots in the original series indicating that none of the original series is stationary. However, the presence of unit roots is conclusively rejected in the first differences of the series for all the variables in all the models. This suggests that all the money and price variables are integrated of order one. Since all the series are integrated of same order, there is a possible chance of co-integration among the series.

Next, co-integrating regressions were estimated and are reported in Table 2. Further, the series of residuals were obtained from each regression and ADF was applied to test for the presence of unit roots in these residuals. These results are also reported in Table 2.

The table shows that the null hypothesis of no co-integration between the two series is accepted in all cases, except between price variables and M2 measure of money. This suggests that there exist a long run relationship between prices and monetary assets, M2.

Finally, to explore the long run relationship between M2 and prices further, that is, to know the short run dynamics as well as the cause and effect relationship, the Error Correction Model was employed and the results are reported in Table 3.

The table shows the $t$-values for the error correction term along with the significance level. The table also shows the $F$-values for the lags of independent variable along with the significance level. The model was tested for six different lags selected arbitrarily. These lags range from 6 months to 36 months. 
Table 1

Unit Root Tests (Augmented Dickey Fuller) for the Period July 81 - June 98

\begin{tabular}{|c|c|c|c|c|c|c|}
\hline & \multicolumn{3}{|c|}{ Original Series } & \multicolumn{3}{|c|}{ Fist Differences } \\
\hline & Model I & Model II & Model III & Model I & Model II & Model III \\
\hline $\ln \mathrm{CP}$ & 11.61 & 1.56 & -1.55 & $-4.08^{*}$ & $-13.72 *$ & $-13.61^{*}$ \\
\hline $\ln \mathrm{WP}$ & 6.86 & 1.52 & -1.87 & $-4.48 *$ & $-11.08^{*}$ & $-11.06^{*}$ \\
\hline $\ln \mathrm{M} 0$ & 8.27 & -2.80 & 1.23 & $-13.01^{*}$ & $-9.65 *$ & $-10.26^{*}$ \\
\hline $\ln \mathrm{M} 1$ & 4.69 & -1.31 & -1.93 & $-12.43^{*}$ & $-10.73^{*}$ & $-10.65^{*}$ \\
\hline $\ln$ M2 & 3.88 & 0.04 & -2.00 & $-2.14^{*}$ & $-4.49 *$ & $-4.37 *$ \\
\hline \multicolumn{7}{|c|}{ Critical Values } \\
\hline$(0.05)$ & -1.94 & -2.87 & -3.43 & -1.94 & -2.87 & -3.43 \\
\hline
\end{tabular}

$\mathrm{CP}=$ Consumer Price Index, WP = Wholesale Price Ind-ex, M0 = Currency in Circulation.

M1= M0 + Demand and Other Deposits, M2 = M1 + Time Deposits + Foreign Currency Accounts.

Table 2

Results from Cointegration Tests

\begin{tabular}{lcccc}
\hline Y on X & Const. & Slope & CRDW & ADF \\
\hline CP on M0 & -2.05 & 0.63 & 0.08 & -0.63 \\
M0 on CP & 3.54 & 1.52 & 0.09 & -1.11 \\
CP on M1 & -2.94 & 0.67 & 0.05 & -0.96 \\
M1 on CP & 4.87 & 1.40 & 0.05 & -1.36 \\
CP on M2 & -2.16 & 0.58 & 0.13 & $-2.72^{*}$ \\
M2 on CP & 3.79 & 1.70 & 0.13 & $-2.79^{*}$ \\
WP on M0 & -2.42 & 0.67 & 0.08 & -1.76 \\
M0 on WP & 3.92 & 1.44 & 0.08 & -1.49 \\
WP on M1 & -3.35 & 0.71 & 0.04 & -1.01 \\
M1 on WP & 5.23 & 1.32 & 0.04 & -1.46 \\
WP on M2 & -2.53 & 0.61 & 0.09 & $-2.48^{*}$ \\
M2 on WP & 4.23 & 1.60 & 0.09 & $-2.58^{*}$ \\
\hline
\end{tabular}

CRDW = Cointegrating Regression Durbin Watson statistic.

$\mathrm{ADF}=$ Augmented Dickey Fuller test.

Critical Value for ADF is 1.94.

Table 3

Results from Error Correction Models

\begin{tabular}{|c|c|c|c|c|c|c|c|c|}
\hline $\mathrm{Y}$ on $\mathrm{X}$ & $t$-values & Signif & $F$-Values & Signif & $t$-Values & Signif & $F$-Values & Signif \\
\hline & \multicolumn{4}{|c|}{ Lags $=6$} & \multicolumn{4}{|c|}{ Lags $=12$} \\
\hline $\mathrm{CP}$ on $\mathrm{M} 2$ & -1.70 & 0.0904 & 0.42 & 0.8637 & -1.36 & 0.1759 & 1.93 & 0.0337 \\
\hline M2 on CP & 2.67 & 0.0081 & 1.01 & 0.4203 & 3.12 & 0.0022 & 1.53 & 0.1185 \\
\hline WP on M2 & -2.59 & 0.0104 & 1.90 & 0.0820 & -2.16 & 0.0324 & 2.64 & 0.0030 \\
\hline \multirow[t]{2}{*}{ M2 on WP } & 1.85 & 0.0652 & 1.49 & 0.1850 & 2.30 & 0.0229 & 0.74 & 0.7096 \\
\hline & \multicolumn{4}{|c|}{ Lags $=18$} & \multicolumn{4}{|c|}{ Lags $=24$} \\
\hline CP on M2 & -1.43 & 0.1542 & 2.13 & 0.0073 & -1.59 & 0.1145 & 1.30 & 0.1762 \\
\hline M2 on CP & 2.04 & 0.0435 & 1.16 & 0.3013 & 1.56 & 0.1208 & 1.14 & 0.3065 \\
\hline WP on M2 & -1.74 & 0.0837 & 2.05 & 0.0140 & -1.75 & 0.0826 & 1.26 & 0.2051 \\
\hline \multirow[t]{2}{*}{ M2 on WP } & 1.34 & 0.1836 & 0.56 & 0.9249 & 1.32 & 0.1883 & 0.55 & 0.9562 \\
\hline & \multicolumn{4}{|c|}{ Lags $=30$} & \multicolumn{4}{|c|}{ Lags $=36$} \\
\hline CP on M2 & -1.93 & 0.0563 & 1.42 & 0.0957 & -2.76 & 0.0069 & 1.41 & 0.0951 \\
\hline M2 on CP & 1.01 & 0.3128 & 1.14 & 0.3036 & 1.29 & 0.1989 & 1.15 & 0.2904 \\
\hline WP on M2 & -2.03 & 0.0444 & 1.29 & 0.1744 & -2.80 & 0.0062 & 1.07 & 0.3838 \\
\hline M2 on WP & 0.94 & 0.3479 & 1.06 & 0.4049 & 1.42 & 0.1579 & 1.25 & 0.1953 \\
\hline
\end{tabular}


The table shows that the error term has the correct negative sign in the regressions of price variables on money. Further it is significant upto 10 percent in all cases where wholesale prices are regressed on money whereas it is significant for lags 6, 30 and 36 in the case of CPI. Regarding lags value of money, these are found significant upto 10 percent at lags 6,12 , and 18 when wholesale prices are regressed on money and at lags $12,18,30$, and 36 in the case of CPI. None of the lags of prices are significant in any money equation. The error term in the money equation, although significant in some cases, does not have the negative sign anywhere.

Overall, the results suggest a unidirectional causality running from money to prices. Further, it seems that the monetary expansion has a greater impact on wholesale sale prices compared to CPI. This is somewhat similar to the finding of Jones and Khilji (1988) where they found the impact of money growth on WPI, but not on CPI. However, their finding of feedback from CPI to money growth is not supported here.

\section{SUMMARY AND CONCLUSIONS}

The objective of the paper is to re-examine the causal relationship between money and prices in Pakistan using recent data and employing cointegration and error correction models. Two measures of prices (CPI and WPI) and three measures of money stocks (M0, M1, and M2) were taken for the period July 1981 to June 1998.

The analysis indicates a long run relationship between prices and M2 definition of money. The other definitions of money do not seem to be related with prices. The analysis further suggests a unidirectional causality running from money to prices and thus supporting the monetarists's claim regarding the role of money. The results, however, are different from the findings of earlier studies in Pakistan which generally report bidirectionl causality between prices and money.

\section{REFERENCES}

Aghevli, B., and M. S. Khan (1978) Government Deficits and the Inflationary Process in Developing Countries. International Monetary Fund Staff Papers 383-416.

Ali, Shaukat (1986) Causality between Money Supply and Price Level: Evidence in Theory and Practice. Kashmir Economic Review 45-53.

Bengali, K., A. Khan, and M. Sadaqat (1997) Money, Income, Prices, and Causality: The Pakistani Experience. (Unpublished Paper.)

Brillembourg, A., and M. S. Khan (1979) The Relationship between Money, Income, and Prices: Has Money Mattered Historically? Journal of Money, Credit and Banking 358-365. 
Engle, R., and C. Granger (1987) Co-integration and Error Correction: Representation, Estimation and Testing. Econometrica 55: 251-276.

Jones, J., and N. Khilji (1988) Money Growth, Inflation, and Causality (Empirical Evidence for Pakistan 1973-85. The Pakistan Development Review 28:1 45-58.

Khan, A. H., and A. N. Siddiqui (1990) Money, Prices and Economic Activity in Pakistan: A Test of Causal Relation. Pakistan Economic and Social Review 121136.

Lee, S. Y., and W. K. Li (1983) Money, Income, and Prices and their Lead-Lag Relationship in Singapore. Singapore Economic Review 73-87.

Pakistan, Government of (Various Issues) Monthly Statistical Bulletin. Federal Bureau of Statistics.

Pakistan, Government of (Various Issues) Monthly Statistical Bulletin. State Bank of Pakistan.

Ramachandran, M. and B. Kamaiah (1992) Causality between Money and Prices in India: Some Evidence from Cointegration and Error Correction Models. Singapore Economic Review 101-108. 